\title{
DIAGNOSTIC VALUE OF C-REACTIVE PROTEIN IN PATIENTS WITH ANGIOGRAPHICALLY DOCUMENTED CORONARY HEART DISEASE
}

\author{
Esin Eren ${ }^{1}$, Necat Yllmaz, ${ }^{1}$, Sadrettin Pence ${ }^{2}$, Hasan Kocoglu ${ }^{3}$, Sttkı Göksu ${ }^{3}$, Ramazan Kocabaș ${ }^{1}$, Sinan Kadayıfcı ${ }^{4}$ \\ Gaziantep University Medical School, Gaziantep, Turkey: Department of Biochemistry ${ }^{1}$, Department of Physiology², \\ Department of Anestesiology and Reanimation ${ }^{3}$; Gaziantep State Hospital: Department of Cardiology ${ }^{4}$
}

\begin{abstract}
Summary: Aim: The aim of this study was to evaluate the diagnostic value of serum C-reactive protein (CRP) level measurement in predicting coronary artery disease (CAD) that can be shown angiographically. Methods: CRP levels were determined in the blood of 198 patients (patients group, PG) with angiographically documented coronary artery disease and compared with that of 85 patients (control group, CG) who had a clinical indication for coronary angiography but have no angiographically determined coronary artery stenosis, as well as with that of 41 healthy volunteers as a healthy control group (HG) who did not have any complaint and did not have coronary angiography. CRP levels were measured 24 hours prior to angiography in PG and CG patients, and in the morning after not having eaten for same time. Any coronary artery stenosis or plaque formation was defined as CAD. Severity of the disease was assessed by both the number of diseased vessels ( 0 to 3 ) and the degree of stenosis ( $<50 \%$ mild, $50-70 \%$ moderate and $>70 \%$ severe). Results: Receiver Operating Characteristics (ROC) curves of CRP in angiographically documented CAD group showed a diagnostic value of 0.659 in female patients, followed by 0.542 in male patients, in predicting CAD. CRP levels were found to be significantly different between groups, higher in PG $(6.2 \pm 0.86 \mathrm{mg} / \mathrm{L})$ than those of CG $(3.7 \pm 0.92 \mathrm{mg} / \mathrm{L})$ and $\mathrm{HG}(0.854 \pm 0.2$ $\mathrm{mg} / \mathrm{L})(\mathrm{p}<0.05)$. CRP levels were not associated with the number of diseased vessels, neither with the degree of the occlusion ( $p>0.05$ ). Multiple logistic regression analysis after adjustment for the established coronary risk factors showed CRP as an independent discriminating risk factor for CAD. Conclusion: It is concluded that CRP measurement has a value in predicting the presence of angiographically documented CAD. However, CRP levels were not associated with the degree or severity of CAD.
\end{abstract}

Key words: C-Reactive Protein; CRP; Sensitivity; Specificity; Diagnosis; Coronary Artery Disease; CAD; Angiography

\section{Introduction}

Many lines of evidence, ranging from in vitro experiments to pathological analysis and epidemiological studies show that atherosclerosis is an intrinsically inflammatory disease.

Over the last few years, $\mathrm{C}$-reactive protein (CRP) assays have been tested in a series of large-scale prospective clinical studies which demonstrated the importance of this marker in predicting risk of heart attack, stroke and peripheral vascular diseases. It is increasingly recognised that CRP may not merely represent an indication of inflammation but may also, because of its known functional properties, be actively involved in the initiation or perpetuation of local inflammatory reactions $(11,26)$. It is known that CRP is a ligand for specific receptors on phagocytic leukocytes, mediates activation reactions on monocytes and macrophages, and activates complements. There is now overwhelming evidence that an inflammatory outburst is associated with acute coronary diseases such as myocardial infarction (MI) and unstable angina pectoris. Although, all of the potential triggers of inflammation are not fully known, and cytokines, oxidized lipoproteins, and local (arterial) and distant infections (gingivitis, bronchitis) have been implicated, the circulating CRP, an acute phase reactant produced by the liver in response to interleukin-6 (a cytokine induced by interleukin-1 and tumor necrosis factor-alpha), has the most consistent relationship to the future risk of CAD, under diverse clinical settings $(4,25,27)$.

It is possible that CRP contributes to pathogenesis of CAD with different effect at every stage of progression. Production of CRP, a nonspecific reaction to various stimuli including infection, tissue damage and smoking may contribute to the initiation and progression of coronary artery disease. Acute phase proteins and CRP are stimulators of tissue factor production from mononuclear cells, an important initiator of coagulation. It also interacts with LDL and damaged membranes to activate the complement system. Results of various studies suggest that CRP levels not only reflect the presence of subclinical atheroma but 
also the likelihood of clinical disease development $(3,6,27)$. In normal healthy individuals, CRP is a trace protein with a range of up to $5 \mathrm{mg} / \mathrm{L} .90 \%$ of apparently healthy subjects have levels of less than $3 \mathrm{mg} / \mathrm{L}$, and $99 \%$ of them have that level less than $10 \mathrm{mg} / \mathrm{L}$. There is no difference between levels in healthy men and healthy women, and no variation with age.

Many questions are still unanswered, including whether CRP is a culprit molecule or simply a marker, and the cutoff points and specificity of the methods are still debated. Drugs and other treatments have little or no affect on CRP production unless they also affect the disease process which is responsible for induction of CRP synthesis. It is thus of great interest that the serum level of CRP has been found to be higher in subjects having no complaint but at greater risk of developing MI, stroke and peripheral vascular disease $(4,27)$.

The aim of this study was to compare CRP concentration in patients with $\mathrm{CAD}$, documented by coronary angiography, with that of patients with normal angiograms but having complaints related to ischemic heart disease, as well as with that of normal healthy individuals, to determine the diagnostic value of CRP levels in the progression of CAD. We also aimed to study the association of this marker with the number of diseased vessels and the degree of stenosis.

\section{Material and Methods}

The study was designed to evaluate the serum CRP levels of individuals of three different groups. 198 patients were included in the Patient Group (PG) who had documented CAD proven by coronary angiography. The Control Group (CG) consisted of 85 patients with clinical indications for angiography, but normal coronary angiogram. Fortyone healthy subjects were included in the Healthy Group (HG).

Although the healthy subjects did not have coronary angiograms, they underwent a comprehensive physical examination by a physician, and completed the World Health Organisation standards Rose questionnaire on chest pain, and answered other questions about their past medical history. None of the individuals in the healthy group had angina or a prior history of CAD. All of them had normal electrocardiograms based on the Minnesota Coding Criteria.

All Coronary Angiographies were performed in the same centre. Patients diagnosed with acute coronary syndrome six months prior to the study were excluded.

All patients were monitored for somatic illness throughout the investigation period and excluded if symptoms of infection or systemic illness were present (rheumatic disease, chronic liver disease, renal disorder, cancer, etc). Additional exclusion criteria included the use of statins and other medications that could affect CRP concentrations.
Severity of the disease was assessed by counting both the number of diseased vessels ( 0 to 3 ) and the degree of the stenosis ( $<50 \%$ mild, $50-70 \%$ moderate and $>70 \%$ severe ) (13).

Prior medical history, personal characteristics and habits were obtained by the questionnaire.

The presence of obesity, diabetes mellitus, and hypertension were also assessed. Obesity was defined as body mass index (BMI) greater than $27.8 \mathrm{~kg} / \mathrm{m}^{2}$ as proposed by the National Institute's of Health consensus statement. Diabetes was defined as fasting blood glucose $>126 \mathrm{mg} / \mathrm{dL}$ or diagnosis of diabetes needing diet or drug therapy. Hypertension was defined as resting systolic blood pressure $>140 \mathrm{~mm} \mathrm{Hg}$ and/or diastolic blood pressure $>90 \mathrm{~mm} \mathrm{Hg}$ (17). Smoking was defined as being a current smoker and smoking at least 10 cigarettes per day for at least ten years.

\section{Standard Blood Sampling}

After an eight-hour fast venous blood samples were collected into vacuum tubes in the morning time on the day before the angiographic procedure on the $\mathrm{PG}$ and the $\mathrm{CG}$ patients. Blood was centrifuged at $3000 \mathrm{~g}$ for 10 minutes at $4{ }^{\circ} \mathrm{C}$. After separation, the aliquoits were frozen at $-70{ }^{\circ} \mathrm{C}$ until analysis.

\section{Measurements}

Serum CRP concentrations were determined with BNA 100 Nephlometer (Dade Behring, Germany) according to the manufacturer's instructions. The assay was linear from 0.175 to $230 \mathrm{mg} / \mathrm{L}$, calibrators and controls (R-CL-I) were supplied by the manufacturer. Specifications of intra assay and inter assay coefficients of variation of CRP assay were assessed from quality control data of the laboratory which were $3.4 \%$ and $6.2 \%$, respectively. The levels of glucose, urea, creatinine, CK, CK-MB, LDH, cholesterol, trygliceride, high-density lipoprotein cholesterol (HDL-C) both in PG and CG were analyzed by BM/902 (ROCHE Diagnostic Systems, Germany). Low-Density lipoprotein cholesterol (LDL-C) was calculated using Friedewald formula if tryglicerides were $<400 \mathrm{mg} / \mathrm{d}(9)$.

\section{Statistical Analysis}

Values are expressed as mean \pm SD for normally distributed variables, and log mean CRP serum levels at $20^{\text {th }}$ and $80^{\text {th }}$ percentiles are given.

Because the distribution of CRP is rightward skewed, values derived from log-transformed means were used as means for this variable throughout the study; these values virtually coincided with median values. A general linear model was used to consider case control differences after adjustment for other factors and the area under the ROC curves were used for comparison of the diagnostic values of different analyses (including PG and CG groups using angiography as the highest accepted standard). Optimal cut-off levels, sensitivity and specificity of CRP were selected based on ROC curves. 


\section{Results}

No statistically significant difference was noted in HDL-C levels among the three groups. However, age, diabetes, hypertension, BMI, total cholesterol and trygliceride levels were significantly different in three groups (Table 1). Smokers consisted of $47 \%$ in the PG, 16\% in the CG, and $37 \%$ in HG (Table 1).

CRP levels were different in the studied groups, and these differences remained statistically significant after correction (ANOVA) for other risk factors (Table 2). CRP levels were not related to the number of diseased vessels and degree of occlusion ( $p>0.05)$ (Table 3 ).

CRP levels were significantly higher in the PG $(6.2 \pm 0.86$ $\mathrm{mg} / \mathrm{L})$ than in the $\mathrm{CG}(3.7 \pm 0.92 \mathrm{mg} / \mathrm{L})$ and the $\mathrm{HG}$ $(0.85 \pm 0.2 \mathrm{mg} / \mathrm{L})(\mathrm{p}<0.05)$ (Figure 1 , Table 2$)$. The number of subjects with concentrations of CRP $\geq 10 \mathrm{mg} / \mathrm{L}$ comprised of $\mathrm{HG}, \mathrm{CG}$ and $\mathrm{PG}$ groups were $0.2 \%, 9 \%$, and $11 \%$ in the $\mathrm{HG}, \mathrm{CG}$ and $\mathrm{PG}$ respectively.
Optimal cut-off levels of CRP providing the maximum efficiency were found in female and male patients with CADs of $6.9 \mathrm{mg} / \mathrm{L}$ and $6.4 \mathrm{mg} / \mathrm{L}$, respectively (Figure 2). The area under the ROC curve was 0.659 in females and 0.542 in male patients (Figure 3 and 4 respectively). ROC curve based specificity of CRP levels ( $38 \%$ for male, $49 \%$ for female) was rather lower than the sensitivity of CRP levels ( $76 \%$ male, $78 \%$ for female) (Table 4 ).

A significant difference was seen in the gender-related difference of CRP concentrations in the PG (Table 5), and these differences were statistically significant after correction with ANCOVA for age, blood pressure, BMI, smoking, glucose, lipids concentration, number of diseased vessels and degree of occlusion.

CRP did not correlate with other continuous variables such as total cholesterol, (r: 0.095, p: 0.15), triglycerides (r: 0.07, p: 0.21), BMI (r: 0.09, p: 0.17), HDL-c (r: -0.087, p: 0.243), LDL-c (r: 0.07, p: 0.283), glucose (r: 0.06, p: 0.389).

Tab. 1: Baseline patients and normal controls characteristics (mean $\pm \mathrm{SD}$ ).

\begin{tabular}{|l|c|c|c|}
\hline & $\begin{array}{c}\text { Healthy Control Group (HG) } \\
\mathrm{n}: 41\end{array}$ & $\begin{array}{c}\text { Control Group (CG) } \\
\text { n: } 85\end{array}$ & $\begin{array}{c}\text { Patient Group (PG) } \\
\text { n: } 198\end{array}$ \\
\hline Age $($ year) & $33.9 \pm 1.3^{*}$ & $52.2 \pm 9$ & $57.3 \pm 6$ \\
\hline Gender (\%) & $20 \mathrm{~F} / 21 \mathrm{M}(0,95)$ & $46 \mathrm{~F} / 39 \mathrm{M}(1.17)$ & $47 \mathrm{~F} / 151 \mathrm{M}(0.32)$ \\
\hline Current smoker (\%) & 37 & 16 & $2151.2 \pm 41.0$ \\
\hline Cholesterol (mg/L) & $1736.8 \pm 47.0^{*}$ & $2221.8 \pm 69.0$ & $1313.5 \pm 33.8$ \\
\hline LDL-C (mg/L) & $1100 \pm 40.7^{* *}$ & $1314.7 \pm 62.4$ & $394.1 \pm 10.5$ \\
\hline HDL-C (mg/L) & $396.6 \pm 16.4$ & $424.3 \pm 20.5$ & $2287.3 \pm 85.9$ \\
\hline Triglycerides (mg/L) & $1200.2 \pm 80.5^{*}$ & $2574.6 \pm 224.7$ & $5.9 \pm 0.1$ \\
\hline Cholesterol/HDL-C & $4.6 \pm 0.2^{* *}$ & $6.2 \pm 0.5$ & $24(12)$ \\
\hline Diabetes $(\%)$ & $3(7.3)^{* * *}$ & $9(10)$ & $27.6 \pm 3.8$ \\
\hline BMI $\left(\mathrm{kg} / \mathrm{m}^{2}\right)$ & $24 \pm 4.1^{* * *}$ & $27.1 \pm 3.5$ & $96(48)$ \\
\hline Hypertension $(\%)$ & $10(24)^{* * *}$ & $41(48)$ & $22(11)$ \\
\hline CRP $(\geq 10 \mathrm{mg} / \mathrm{L}, \mathrm{n}, \%)$ & $1(0.2)^{*}$ & $8(9)$ & \\
\hline
\end{tabular}

* $\mathrm{p}<0.001 \mathrm{HG}$ versus $\mathrm{CG}, \mathrm{PG}$

$* * p<0.005 \mathrm{HG}$ versus CG,PG

$* * * p<0.01 \mathrm{HG}$ versus CG,PG

Tab 2: Serum CRP concentrations $(\text { mean } \pm \mathrm{SD})^{*}$.

\begin{tabular}{|c|c|c|c|}
\hline & $\begin{array}{c}\mathrm{HG} \\
\mathrm{n}: 41\end{array}$ & $\begin{array}{c}\text { CG } \\
\mathrm{n}: 85\end{array}$ & $\begin{array}{c}\mathrm{PG} \\
\mathrm{n}: 198\end{array}$ \\
\hline ** CRP $(\mathrm{mg} / \mathrm{L})$ & $0.85 \pm 0.2$ & $3.7 \pm 0.92$ & $6.2 \pm 0.86$ \\
\hline
\end{tabular}

* (mean \pm SD denote values derived from log transformed)

$* * p<0.001$ PG versus HG

$* * p<0.05$ PG versus CG

$* * p<0.01 \mathrm{CG}$ versus HG
Tab. 3: Serum CRP and severity of coronary artery diseases.

\begin{tabular}{|l|r|c|}
\hline & \multicolumn{1}{|c|}{$\mathrm{n}$} & $\begin{array}{c}\text { CRP }(\mathrm{mg} / \mathrm{L}) \\
(\text { mean } \pm \mathrm{SD})^{*}\end{array}$ \\
\hline One vessel & 38 & $7.3 \pm 3.7$ \\
\hline Two vessel & 54 & $5.2 \pm 3.1$ \\
\hline Three vessel & 106 & $6.2 \pm 1.9$ \\
\hline$<50 \% * *$ & 26 & $5.4 \pm 4.9$ \\
\hline$\geq 50 \%$ and $<70 \% * *$ & 17 & $5.2 \pm 3.1$ \\
\hline$\geq 70 \% * *$ & 155 & $6.2 \pm 1.9$ \\
\hline
\end{tabular}

*(mean \pm SD denote values derived from log transformed)

**Degree of occlusion 
Tab. 4: Optimal cut-off levels and the associated specificity, sensitivity, diagnostic value of CRP levels for the diagnosis angiographically documented CAD.

\begin{tabular}{|l|c|c|c|c|}
\hline & $\begin{array}{c}\text { Cut-off } \\
\text { level } \\
(\mathrm{mg} / \mathrm{L})\end{array}$ & $\begin{array}{c}\text { Speci- } \\
\text { ficity } \\
(\%)\end{array}$ & $\begin{array}{c}\text { Sensi- } \\
\text { tivity } \\
(\%)\end{array}$ & $\begin{array}{c}\text { Diag- } \\
\text { nostic } \\
\text { Value }\end{array}$ \\
\hline Male CRP & 6.4 & 38 & 76 & 0.542 \\
\hline Female CRP & 6.9 & 49 & 78 & 0.659 \\
\hline
\end{tabular}

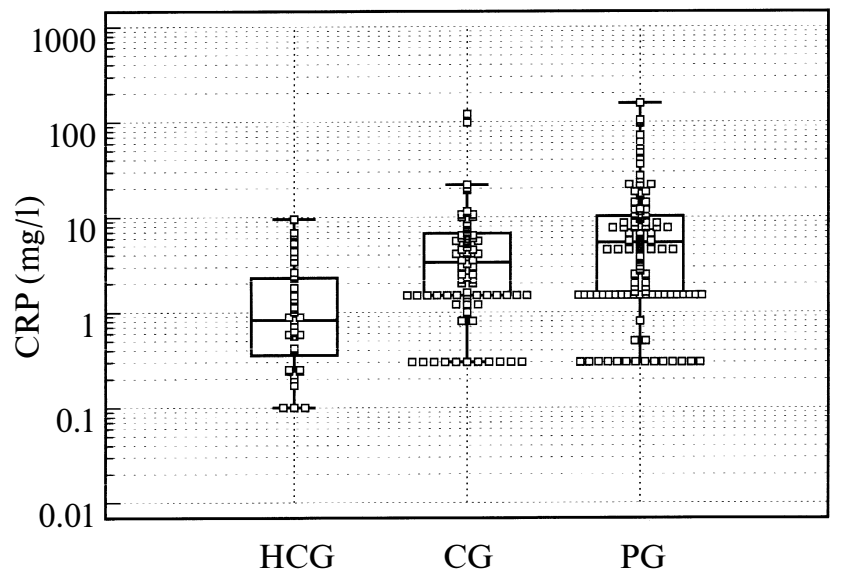

Fig. 1: Distribution of serum CRP concentrations in $P G$, $\mathrm{CG}$ and HG groups. The central box represents the values from the lower to upper quartile (25-75 percentile). The middle line represents the median.

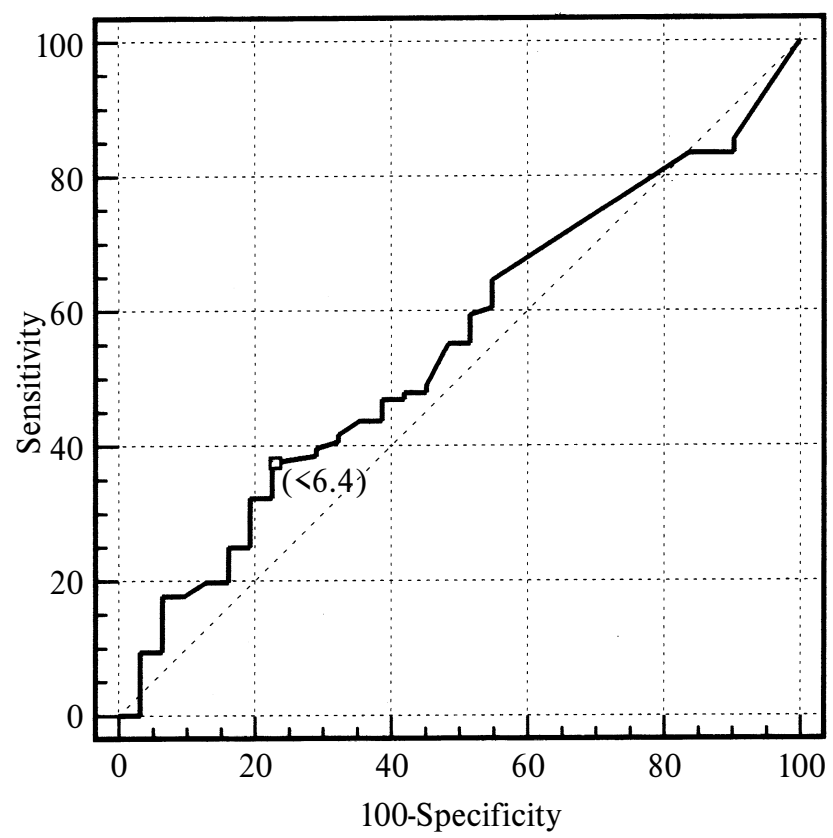

Fig. 3: ROC curve of CRP and optimal cut-off points in male patients.
Tab. 5: Gender related difference of CRP concentrations in the patient group $(\text { mean } \pm \mathrm{SD})^{*}$.

\begin{tabular}{|c|c|c|c|}
\hline & Male & Female & \\
& n: 151 & n: 47 & \\
CRP (mg/L) & $6.1 \pm 1.7$ & $7.2 \pm 3.6$ & $\mathrm{p}<0.05$ \\
\hline
\end{tabular}

*(mean \pm SD denote values derived from long transformed)

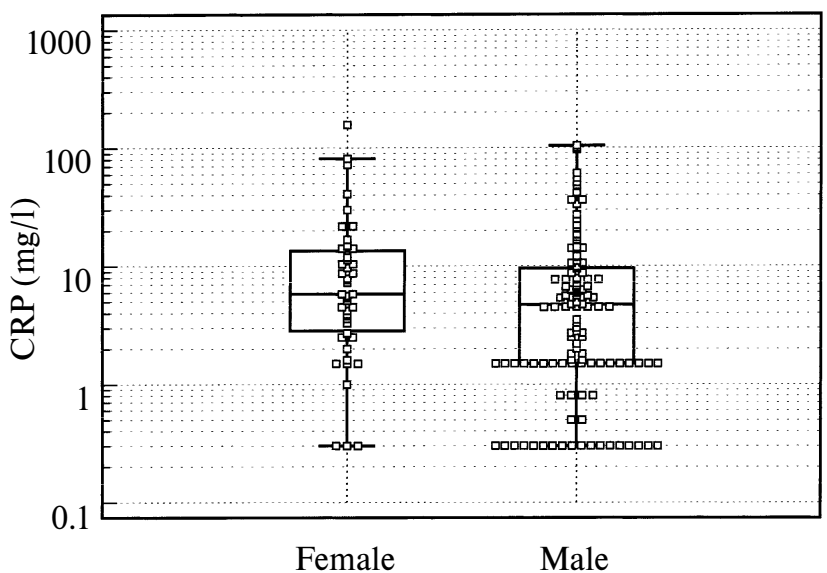

Fig. 2: Distribution of serum CRP concentrations in PG, male and female groups. The central box represents the values from the lower to upper quartile (25-75 percentile). The middle line represents the median.

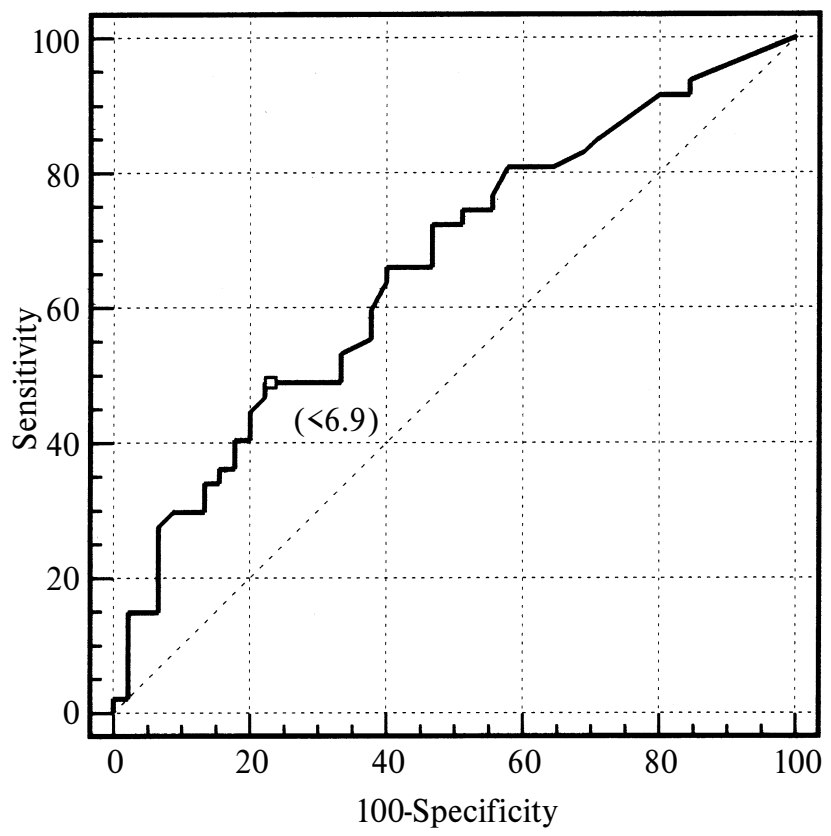

Fig. 4: ROC curve of CRP and optimal cut-off points in female patients. 


\section{Discussion}

The data from our study demonstrated that the serum concentrations of CRP were increased during atherosclerotic process. However these increases failed to reflect the severity of the CAD. Our results also confirm the existing relationship between C-reactive protein levels and the presence of coronary artery disease documented by coronary angiography. The small area under the ROC curve suggest a possible presence of CAD in angiography. It should be pointed out that the differences seen between groups in CRP concentrations remained highly significant after the adjustment for age, smoking, hypertension, diabetes mellitus, BMI, total cholesterol, LDL-C and triglycerides.

Despite changes in lifestyle and the use of new pharmacological approaches to lower plasma cholesterol concentrations, cardiovascular disease continues to be the principal cause of death in Europe, USA and most of Asia. Half of the heart attacs occur in people with normal cholesterol levels (13). Although hyprecholesterolemia is important in approximately $50 \%$ of the patients with $\mathrm{CAD}$, other risk factors need to be taken into consideration (21).

CRP is a sensitive marker for systemic inflammation. Recent work from Pasceri et.al. indicates that CRP itself might be involved in the pathogenic response. In their study they suggested that CRP could induce adhesion molecule expression in endothelial cells via its effect on monocyte chemoattracting protein 1 . Regardless of the CRP's precise mechanism for inflammatory effects in the vasculature, perhaps the most relevant is the prospect of inflammation as a therapeutic target (18).

The peak plasma CRP values are strongly associated with post-infarct morbidity and mortality (17). In a metaanalysis of 7 prospective studies, elevated serum CRP concentration was shown to predict future risk of CAD (10). C-reactive protein levels below the conventional upper normal limit of $10 \mathrm{mg} / \mathrm{L}$ have been associated with a 2-to-3 fold increase in risk of myocardial infarction, ischemic stroke, peripheral artery diseases and CAD $(18,21)$. Several prospective studies have shown that healthy people with higher serum CRP levels, though usually within the normal reference range, are at an increased risk of developing $\mathrm{MI}$, stroke or peripheral vascular disease $(1,5,14,22)$.

Rifai et al. demonstrated higher plasma concentration of CRP in men with angiographically documented CAD (20). Similarly, Haideri et.al. found an association of elevated CRP levels with angiographically documented coronary artery disease. They also reported that CRP concentration was positively related to the number of diseased vessels and associated with the degree of stenosis of coronary arteries (12). In this study, although CRP levels were found to be increased in patients with angiographically documented CAD, no correlation could be demonstrated between the CRP concentration and severity of CAD. These findings are in agreement with the results of Rifai and colleagues. We also found that, not with standart the normal coronary angiograms, the CG patients had elevated CRP levels, which has not been reported before $(12,20)$.

It has been reported in previous studies that there was no sex-related difference nor association between the CRP levels and age in healthy individuals $(7,15,16)$. However Onat et al. reported that gender is a significant independent determinant of CRP levels in a healthy population in western Turkey (17). In the NHLBI Family Heart Study, CRP values were associated with age, family type, and gender (8). Our study showed that CRP levels in male individuals were higher than that of females in HG individuals. ROC curves (figure 3,4) showed a low level of sensitivity and specificity in the present study, and showed uselessness to diagnose angiographically significant $\mathrm{CAD}$. The area under the ROC curve was 0.542 in males in comparison to 0.659 in females in PG $(p<0.05)$. To best of our knowledge these data were not reported in the literature so far.

One possible explanation of the increased CRP levels in patients with a clinical indication for cardiac catheterisation but with normal angiograms is the association of CRP levels with ongoing atherosclerosis. The increase in CRP levels in these individuals may reflect the diffuse atherosclerotic process in the vascular system rather than the degree of the localised obstruction.

In one study a cut-off value of $15 \mathrm{mg} / \mathrm{L}$ was chosen on the basis of ROC curves in patients with unstable angina and myocardial infarction (7). Recommended reference limits for serum CRP levels appeared to be insufficient for discriminating subjects with and without CAD because of considerable overlaps. In contrast to these findings, we found optimal cut-off levels for ROC curves to be 6.4 $\mathrm{mg} / \mathrm{L}$ for males, and $6.9 \mathrm{mg} / \mathrm{L}$ for females with CAD. However, the potential limitations of this study warrant consideration. Although CRP was an independent discriminator between the PG and the CG patients, there was considerable overlap in CRP concentrations between the two populations. The presence of occult or ongoing coronary artery disease in the CG could not be excluded and may have attenuated the differences among the two groups, whereby the diagnostic value of CRP in CAD may be underestimated.

\section{Conclusions}

In conclusion, serum CRP level measurement appears to have an important diagnostic value in predicting the presence of angiographically detectable coronary artery disease. However, the higher levels of serum CRP seem not to be associated with the degree or severity of coronary artery disease.

\section{References}

1. Abdelmouttaleb I, Danchin N, Ilardo C, Aimone-Gastin I, Le Faou A. C-reactive protein and coronary artery disease: additional evidence of the implication of an inflammatory process in acute coronary syndromes. Am Heart J 1999;2:346-51.

2. Baltz ML, de Beer FC, Feinstein A et al. Pylogenetic aspects of C-reactive protein and related proteins. Ann NY Acad Sci 1982;389:49-75. 
3. Bhakdi S, Torzewski M, Klouche M, Hemmes M. Complement activation and atherogenesis. Binding of CRP to degraded, nonoxidised LDL enhances complement activation. Arterioscler Thromb Vasc Biol 1999;19:2348-54.

4. Cermak JC, Key NS, Bach RR, Balla J, Jacob HS, Vercellotti GM. C-reactive protein induces human peripheral blood monocytes to synthesize tissue factor Blood 1993;82:513-20.

5. Danesh J, Collins R, Applebly P, Peto R. Association of fibrinogen , C-reactive protein, albumin or leukocyte count with coronary heart disease. Jama 1998;279:1477-88

6. de Beer FC, Soutar AK, Baltz ML, Trayner I, Feinstein A, Pepys MB. Low density and very low density lipoproteins are selectively bound by aggregated $\mathrm{C}$-reactive protein. J Exp Med 1982;156:230-42.

7. Ferreiros ER, Boissonnet CP, Pizarro R et al. Independent prognostic value of elevated C-reactive protein in unstable angina. Circulation 1999;100(19):1958-63.

8. Folsom AR, Pankow JS, Tracy RP et al. Association of C-reactive protein with markers of prevalent atherosclerotic disease. Am J Cardiol 2001;88(2):112-7.

9. Friedewald WT, Levy RI, Fredrickson DS. Estimation of the concentration of low-density lipoprotein cholesterol in plasma, without use of the preparative ultracentrifuge. Clin Chem 1972;18(6):499-502.

10. Griselli M, Herbert J, Hutchinson WL et al. C-reactive protein and complement are important mediators of tissue damage in acute myocardial infarction. J Exp Med 1999;190(12): 1733-40.

11. Hack CE, Wolbink GJ, Schalkwijk C, Speijer H, Hermens WT, van den Bosch H. A role for secretory phospholipase A2 and C-reactive proteins in the removal of injured cells. Immunol Today 1997;18:111-5.

12. Haidari M, Jaradi E, Sadeghi B, Hajilasi M, Ghanbili J. Evaluation of C-reactive protein asensitive marker of inflammation as risk factor for stable coronary artery disease. Clin Biochem 2001;33:309-15.

13. Judkins MP. Selective coronary arteriography. I. A percutaneous transfemoral technique. Radiology 1967:89:815-24.

14. Kuller LH, Tracy RP, Shaten J, Meilahn EN. Relation of C-reactive protein and coronary heart disease in the MRFIT nested case-control study. Am J Epidemio 1996; 144:537-47.

15. Kuller LH, Tracy RP. The role of inflammation in cardiovascular disease Arterioscler Thromb Vasc Biol 2000;20(4):901-6.

16. Macy EM, Hayes TE, Tracy RP. Variability in the measurement of C-reactive protein in healthy subjects: implications for reference intervals and epidemiological applications. Clin Chem 1997;43(1):52-8.

17. Onat A, Sansoy V, Yildirim B, Keles I, Uysal O and Hergenc G. C-reactive protei and coronary heart disease in western Turkey. Am J Cardiol 2001;88(6):601-7.
18. Pasceri V, Wu HD, Willerson JT, Yeh ET. Modulation of vascular inflammation in vitro and in vivo by peroxisome proliferator-activated receptor-gamma activators. Circulation 2000; 101:235-8.

19. Pepys MB, The acute phase response with special reference to C-reactive protein and related proteins (pentaxins) and serum amyloid A protein. Adv Immuno 1983;34:141-212.

20. Pepys MB, Dash AC, Fletcher TC, Richardson N, Munn EA, Feinstein A Analogs in other mammals and in fish of human plasma proteins C- reactive protein and amyloid P component. Nature. 1978;273:168-70

21. Ridker PM, Hennekens CH, Buring JE, Rifai N. C-reactive protein and other markers of inflammation in the prediction of cardiovascular disease in women. N Engl J Med 2000;342(12):836-43.

22. Ridker PM, Cushman M, Stampfer MJ, Tracy RP, Hennekens CH. Plasma concentration of C-reactive protein and risk of developing peripheral vascular disease. Circulation 1998;97:425-8

23. Rifai N, Joubran R, Yu H, Asmi M, Jouma M. Inflammatory markers in men with angiographically documented coronary heart disease. Clin Chem. 1999;45(11): 1967-73.

24. Rifai N, Tracy RP, Ridker PM. Clinical efficacy of an automated high sensitivity C-reactive protein assay. Clin chem 1999;45(12):2136-41

25. Shah PK. Circulating markers of inflammation for vascular risk prediction: Are they ready for prime time. Circulation 2000;101(15):1758-65.

26. Thompson D, Pepys MB, Wood SP. The physiological structure of human C-reactive protein and its complex with phosphocholine. Structure 1999;7:169-77.

27. Whicher J, Biasucci L, Rifai N. Inflammation, the acute phase response and at herosclerosis. Clin Chem Lab Med 1999;37(5):495-503.

Submitted October 2001.

Accepted May 2002.

Dr. Necat Yilmaz,

Gaziantep Üniversitesi,

Tip Fakültesi Biyokimya Anabilim Dal, 27310 Gaziantep, Türklye. e-mail: necatyilmaz@hotmail.com 